\title{
Potencial erosivo das chuvas em simulador portátil em diferentes coberturas do solo
}

A erosão hídrica é um fenômeno natural de desagregação, transporte e deposição de sedimentos. Ações antrópicas podem intensificar a velocidade de degradação, ocasionando a perda da camada superficial do solo, arraste de nutrientes e sedimentos e, consequentemente, o assoreamento de rios. O objetivo neste trabalho foi avaliar a oferta pluvial em Belém/PA e utilizar um simulador portátil de erosão hídrica para mostrar de forma didática e prática as perdas de solo e água usando três coberturas típicas de sistemas pecuários na região. Utilizou-se a série histórica de dados pluviais de Belém/PA, correspondente a 26 anos (1990 a 2016), obtidos das bases do Instituto Nacional de Meteorologia (INMET). Realizou-se análise exploratória dos dados para extrair medidas de dispersão em anos mais pluviosos capazes de expressar efeitos erosivos. Estimou-se o potencial erosivo das chuvas usando equação de regressão para a região. Para conscientizar os agricultores e sociedade em geral sobre a importância da manutenção do solo, usou-se um simulador portátil de chuva para avaliar perdas de solo e água, no qual foram Para conscientizar os agricultores e sociedade em geral sobre a importância da manutenção do solo, usou-se um simulador portátil de chuva para avaliar perdas de solo e água, no qual foram
realizadas duas simulações, a primeira usando um volume de água de $25,11 \mathrm{~mm}$ em $30 \mathrm{~min}$, simulando uma chuva fraca e a segunda usando um volume de água de $56,50 \mathrm{~mm}$ em $10 \mathrm{~min}$ simulando uma chuva torrencial, em três parcelas, uma com solo exposto, e as demais com capim-mombaça (Panicum maximum) e gramínea paisagística (Axonopus compressus), em dois períodos distintos, agosto de 2015 e maio de 2016. Foram coletadas após as simulações soluções contendo solo e água, as quais foram submetidas às análises de turbidez, sólidos totais dissolvidos, $\mathrm{pH}$, condutividade elétrica e solo seco erodido. Os resultados obtidos na estimativa do potencial erosivo das chuvas indicaram que as chuvas diárias acima de 30 mm são mais ocorrentes no mês maio e, consequentemente resulta em maiores erosividades nesse período em toda série histórica. Nesses anos a precipitação pluvial em agosto foi de 134,34 mm (2015) e 313,54 mm no mês de maio (2016). Nas simulações, o processo erosivo é mais intenso no período chuvoso em relação ao menos chuvoso em solo exposto, seguido do capim-mombaça para as condições em que foram realizadas as simulações em Belém/PA. A gramínea apresenta maior capacidade de retenção de solo em eventos pluviosos simulados. Desta forma, concluiuse que o simulador é uma boa ferramenta visual para mostrar a dinâmica da perda do solo, facilitando o entendimento da população sobre a importância da cobertura do solo e da preservação ambiental.

Palavras-chave: Precipitação; Energia Cinética; Erosividade; Educação Ambiental.

\section{Erosive potential of precipitation in portable simulator in different soil covers}

\begin{abstract}
Water erosion is a natural phenomenon of sediment disintegration, transport and deposition. Anthropogenic actions can intensify the degradation speed, causing the loss of the superficial layer of the soil, drag of nutrients and sediments and, consequently, the silting of rivers. We sought to evaluate the rainfall supply in Belém/PA and to use a portable water erosion simulato to show in a didactic and practical way the losses of soil and water using three typical coverages of livestock systems in the region. We used a historical series of rainfall data from Belém/PA with 26 years (1990 to 2016), obtained from the bases of the National Institute of Meteorology (INMET). We conducted an exploratory analysis of the data to extract dispersion measurements in more pluvial years capable of expressing erosive effects. We did not estimate the erosive potential of rainfall using a regression equation for the region. In order to make farmers and society more aware of the importance of soil maintenance, a portable rainfall simulator was used to evaluate soil and water losses, in which two simulations were carried out, the first using society a watervolu and the solutions containing soil and water, which were submitted to analyzes of turbidity, total dissolved solids, pH, electrical conductivity and eroded dry soil. In the estimation of the erosive potential of the rains indicated that daily rains above $30 \mathrm{~mm}$ are more occurring in May and, consequently, results in higher erosivities in this period in all historical series. In those years the rainfall in August was $134.34 \mathrm{~mm}$ (2015) and $313.54 \mathrm{~mm}$ in the month of May (2016). In the simulations, the erosion process is more intense in the rainy season compared to the less rainy in exposed soil, followed by the Mombasa grass for the conditions in which the simulations were carried out in Belém/PA. The grass presents greater capacity of retention of soil in simulated pluvial events. We conclude that the simulator is a good visual tool to show the dynamics of soil loss, facilitating the understanding of the population about the importance of soil cover and environmental preservation.
\end{abstract}

Keywords: Precipitation; Kinetic Energy; Erosion; Environmental Education.

Topic: Engenharia Ambientalrea Temática

Reviewed anonymously in the process of blind peer.

Aline Michelle da Silva Barbosa (iD

Universidade Estadual Paulista, Brasil

http://lattes.cnpq.br/0496495918772522

http://orcid.org/0000-0001-8336-2645

aline.m.barbosa@hotmail.com

Lucieta Guerreiro Martorano (iD

Embrapa Amazônia Oriental, Brasil

http://lattes.cnpq.br/9712490260615310

http://orcid.org/0000-0003-3893-3781

martorano.lucietta@gmail.com

Letícia Souza dos Santos

Universidade Federal do Pará, Brasil

http://lattes.cnpq.br/9946831897598402

llet.santos@gmail.com

8

DOI: 10.6008/CBPC2179-6858.2018.004.0017
Received: $10 / 04 / 2018$

Approved: 24/05/2018

José Reinaldo da Silva Cabral de Moraes

Universidade Estadual Paulista, Brasil

http://lattes.cnpq.br/2670721926559119

http://orcid.org/0000-0002-8567-4893

reinaldojmoraes@gmail.com

Lucas Eduardo de Oliveira Aparecido

Instituto Federal do Mato Grosso do Sul, Brasil

http://lattes.cnpq.br/1805687336632729

lucasedap.bol@hotmail.com

Referencing this:

BARBOSA, A. M. S.; MARTORANO, L. G.; SANTOS, L. S.; MORAES, J. R. S. C.; APARECIDO, L. E. O.. Potencial erosivo das chuvas em simulador portátil em diferentes coberturas do solo. Revista Ibero Americana de Ciências Ambientais, v.9, n.4, p.200-209, 2018. DOI: http://doi.org/10.6008/CBPC2179-6858.2018.004.0017 


\section{INTRODUÇÃO}

Altas precipitações pluviais, principalmente em regiões que possuem características climáticas de chuvas torrenciais podem apresentar riscos maiores de desastres ambientais, como desmoronamento de encostas, assoreamento de corpos hídricos, alagamentos, entre outros (NUNEZ et al., 2003). A principal causa da erosão hídrica é ocasionada pelas chuvas, que desagrega as partículas de solos, ocorrendo arrastes e deposição desse material. Além de partículas em suspensão, o solo perde nutrientes, matéria orgânica, sementes e defensivos agrícolas, deixando o solo com deficiência estrutural e nutricional (BERTONI et al., 2012). A erosão hídrica pode ser intensificada em períodos de eventos extremos isolados com grandes cargas de chuvas em curtos intervalos de tempo. Esse fenômeno pode explicar a perda da capacidade produtiva em solos agrícolas em áreas tropicais (CASSOL et al., 2002).

A região amazônica possui duas estações predominantes no ano, a que apresenta maiores quantidades de chuvas e outra com período de menor oferta pluvial, e essa característica climática pode ser intensificada com os fenômenos de La Niña e El Niño (MARTORANO et al., 1992). A erosão do solo é um fenômeno natural, que pode ocasionar em desastres ambientais, porém a ação antrópica intensifica esse fator natural, deixando o solo ainda mais propício às perdas de suas capacidades originais (MIRANDA et al., 2010). O uso inadequado do solo provoca alterações que podem ser de níveis leves a problemas mais definitivos, desequilibrando sistemas importantes do ambiente (PEREIRA et al., 2009).

Outros fatores que aumentam as taxas de perdas de solo é a compactação por tráfego de máquinas agrícolas, tipo de cobertura, grau de degradação, chuvas intensas, altas temperaturas, condições topográficas e o manejo inadequado do solo (MARTORANO et al., 2009). E as maiores perdas ocorrem na parte superficial, onde está presente o horizonte que possui a maior carga de fertilidade, provocando diminuição de sua capacidade produtiva (HERNANI et al., 2002).

O simulador portátil de erosividade ajuda a entender toda a dinâmica da perda do solo, facilitando os agricultores, estudantes e a população em geral a visualizar, na prática, a diferença do potencial erosivo em diferentes coberturas do solo. Nesse contexto, o objetivo neste trabalho foi avaliar a oferta pluvial e o potencial erosivo das chuvas em Belém/PA e utilizar um simulador portátil de erosão hídrica para exposição de forma didática e prática as perdas de solo e água usando três coberturas típicas de sistemas pecuários na região.

\section{MATERIAIS E MÉTODOS}

A pesquisa foi desenvolvida em uma Unidade de Pesquisa Animal, na Fazenda Senador Álvaro Adolpho, com coordenadas de $01^{\circ} 25^{\prime} 58.2^{\prime \prime}$ S e $48^{\circ} 26^{\prime} 29.6^{\prime \prime}$ W, pertencente a Embrapa Amazônia Oriental, Belém/PA (Figura 1). O solo predominante da área enquadra-se na classe do Latossolo Amarelo, distrófico típico, com textura média, formado por sedimentos cauliníticos, em consolidação. Esses solos apresentam características físicas como: bem drenados e alta profundidade, possibilitando o desenvolvimento de sistema radicular, mas possuem baixa fertilidade química, pH geralmente ácido e baixos teores de fósforo disponível 
(WATRIN et al., 2011). De acordo com Martorano et al. (1993) a área de estudo está sob influência da tipologia climática $\mathrm{Af}_{2}$, com temperaturas médias do ar superiores a $18 \mathrm{C}^{\circ}$, chuvas médias mensais superiores a $60 \mathrm{~mm}$ e, totais anuais médios de $2.921,7 \mathrm{~mm}$. As condições topotérmicas variam entre $26,5^{\circ} \mathrm{C}$ a $26,7^{\circ} \mathrm{C}$ (MARTORANO et al., 2009).

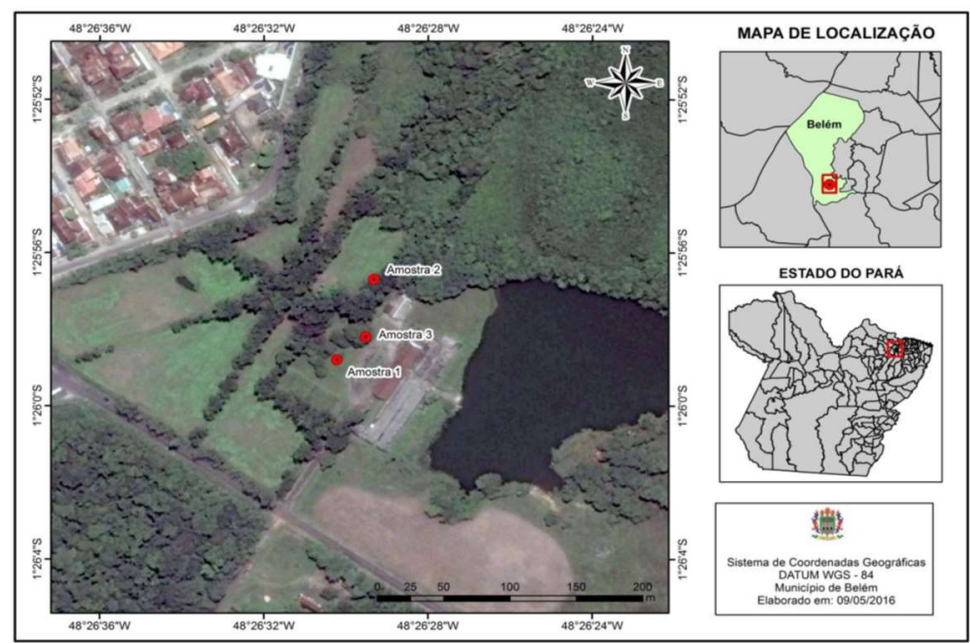

Figura 1: Pontos referentes aos locais de coletas de amostras na Fazenda Álvaro Adolfo, Embrapa Amazônia Oriental em Belém, Pará.

\section{Potencial Erosivo das Chuvas}

Para o levantamento e análises de dados da precipitação pluvial usou-se a série de dados homogênea corresponde ao período de 26 anos (1990 a 2016) no município de Belém/PA, obtidos das bases do Instituto Nacional de Meteorologia (INMET). Realizou-se análise exploratória dos dados para extrair medidas de dispersão em anos mais pluviosos capazes de expressar efeitos decorrentes de processos erosivos. A erosividade das chuvas foi calculada aplicando a Equação 1 ajustada para a obtenção do coeficiente de chuva (Rainfall Coefficient - Rc) para a área de estudo, segundo a metodologia descrita por (OLIVEIRA JUNIOR, 1988).

$$
\mathrm{Rc}=\frac{\left(\mathrm{p}^{2}\right)}{(\mathrm{P})} \quad \text { Equação } 1
$$

Em que Rc é o coeficiente de chuva mensal $(\mathrm{mm}) ; p$ corresponde à média mensal da precipitação pluvial $(\mathrm{mm})$ e $P$ à média anual de precipitação pluvial em $\mathrm{mm}$. Utilizando o coeficiente da chuva (Rc) foi calculado o índice $\mathrm{Ei}_{30}$, (Equação 2), que corresponde ao produto da energia cinética de chuvas erosivas (E) com alta intensidade em um período de máxima em 30 minutos $\left(I_{30}\right)$.

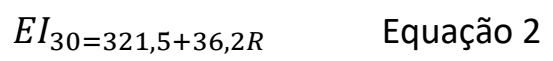

Em que o $\mathrm{Ei}_{30}$ representa a energia cinética de chuvas erosivas de intensidade máxima em um período contínuo de 30 minutos (MJ mm ha-1) e Rc o coeficiente de chuva.

\section{Simulador de erosividade}

O trabalho foi elaborado em dois períodos, seco e chuvoso. A primeira coleta de solo ocorreu no mês de agosto de 2015, no período com menos oferta pluvial, e solo consequentemente mais seco. A segunda 
coleta ocorreu no mês de maio de 2016, no período chuvoso e solo mais úmido. Foram coletadas amostras de solos e realizadas as simulações de erosão hídrica sob diferentes condições para avaliar o comportamento do solo no período seco (solo seco) e chuvoso (solo úmido). Os locais das coletas das amostras foram escolhidos de acordo com as características da área. A amostra 1 foi em área com gramíneas paisagística (Axonopus compressus), também conhecida como grama curitibana e grama-tapete. A amostra 2 em uma área que possuía capim-mombaça (Panicum maximum), e a amostra 3 foi em solo exposto. Os pontos escolhidos foram georreferenciados em coordenadas geográficas com o auxílio do GPS da marca GARMIN. Posteriormente, as amostras foram adicionadas em um simulador de potencial hídrico erosivo para analisar as perdas de solo e água. As amostras foram inseridas no simulador de chuva, o qual é construído com garrafões 'Pet' de 20 litros com blocos de solo contendo um volume de $0,0067 \mathrm{~m}^{3}$, ocupando o equivalente a 7 litros do garrafão.

A primeira simulação de chuva aconteceu no intervalo de 30 minutos utilizando $4.000 \mathrm{~mm}$ de água e intensidade da chuva de $26,9 \mathrm{~mm}$. $\mathrm{h}^{-1}$, ou seja, chegando bem próximo ao $\mathrm{El} 30$, para simular uma chuva com baixa intensidade e a segunda simulação em 10 minutos com $9.000 \mathrm{~mm}$ com alta intensidade da chuva contabilizando-se $182,18 \mathrm{~mm} \cdot \mathrm{h}^{-1}$, simulando uma chuva torrencial. Foram realizados diferentes testes até à quantidade próxima a um evento de precipitação pluvial com curto período de tempo que chegasse próximo ao evento máximo ocorrido em Belém durante a série temporal analisada.

O simulador é constituído de uma estrutura de madeira que contém quatro recipientes de 20 litros, um sistema hidráulico, e três recipientes para coletar a saída de água do sistema. Na parte superior da estrutura, contém um recipiente que exerce a função de reservatório de água, onde está acoplado um sistema hidráulico para simulação de chuva. O sistema hidráulico conduz a água do reservatório para três acessórios (chuveiros) que simulam a gota da chuva nos recipientes distintos onde estão contidas as amostras de solo (Figura 2). Para a coleta da saída de solução líquida das amostras de solo, foram usadas provetas graduadas.

Para extrair os efeitos de diferentes quantidades de jatos d'água nos tubos e chuveiros fizeram-se testes de vazão e verificou-se que nos três chuveiros o maior valor foi de 0,0356 L.s ${ }^{-1}$ (central) e de 0,0333 L.S ${ }^{1}$ nos chuveiros das duas extremidades, aproximadamente. A intensidade da chuva simulada foi calculada a partir da Equação 3.

$$
I=\left(\begin{array}{c}
V / S \\
t
\end{array}\right) \cdot 60
$$

Em que I representa a intensidade de precipitação $\left(\mathrm{mm} / \mathrm{h}^{-1}\right), \mathrm{V}$ o volume de água coletada em litros, $\mathrm{S}$ a área da seção de coleta e t o tempo em que foi realizado o teste. Nas amostras resultantes da simulação foram analisados os parâmetros: pH, Sólidos Totais Dissolvidos (STD) e Condutividade Elétrica em Sonda Multiparâmetro da marca HANNA e a Turbidez foi medida em um Turbidímetro TD-300. As amostras da parte erodida de solo foram analisadas para determinação da porção seca do sedimento. 


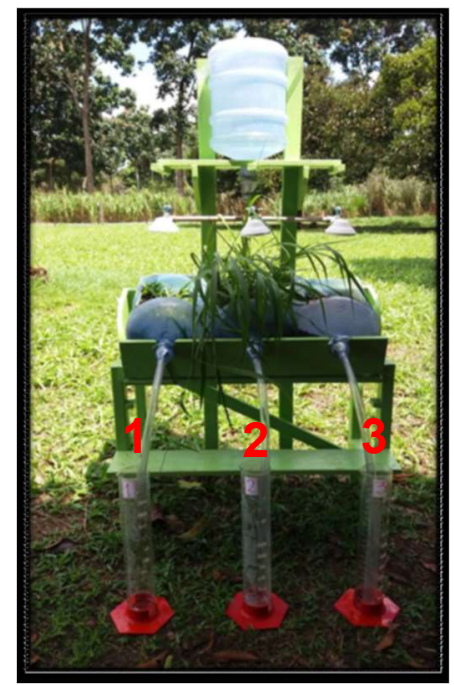

Figura 2: Simulador de chuva portátil. Amostra 1: Gramínea; Amostra 2: Capim-mombaça; Amostra 3: Solo exposto.

\section{RESULTADOS}

As figuras 3, 4, 5, 6 e 7, trazem, resumidamente, todos os resultados obtidos na pesquisa.

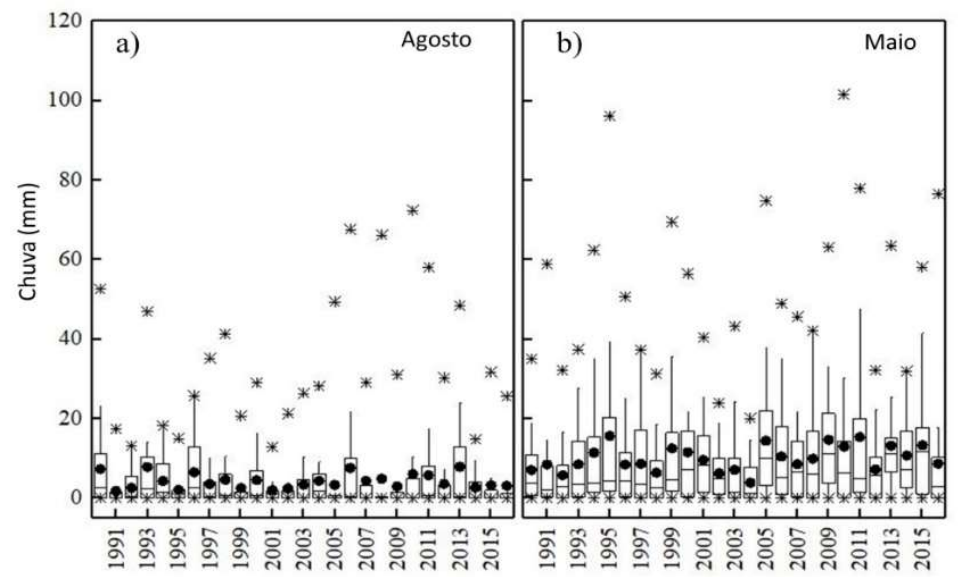

Figura 3: Precipitação Pluvial e Chuvas Máximas na série histórica de 1990-2016 nos meses de agosto e maio, Belém/PA.

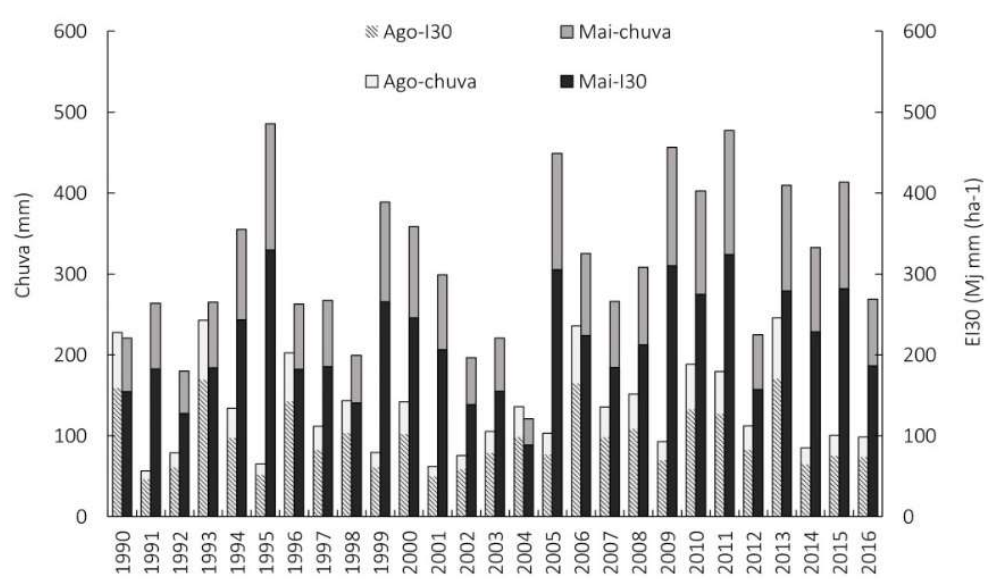

Figura 4: Potencial erosivo anual no município de Belém/PA entre os anos de (1990 a 2016). 


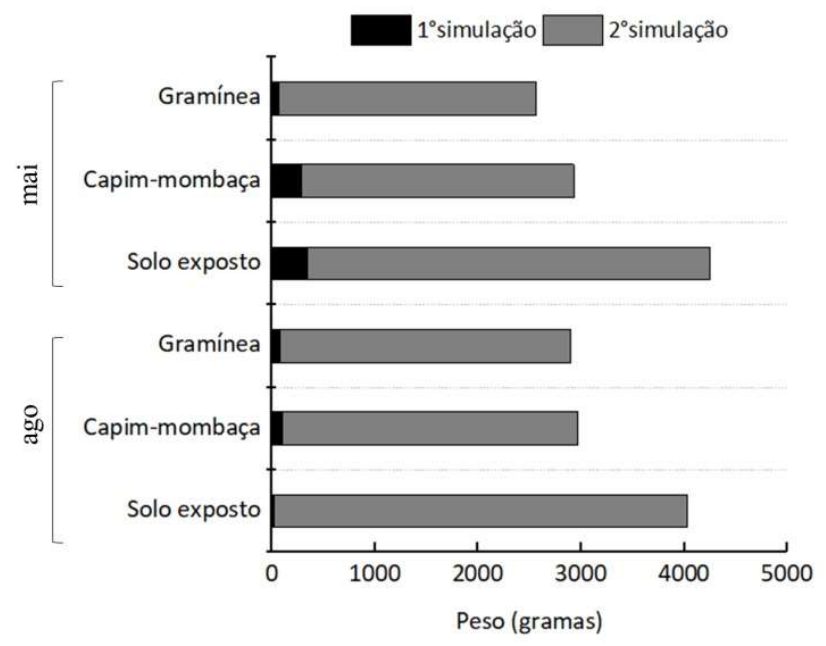

Figura 5: Perdas de água e solo na simulação do processo hídrico erosivo em agosto de 2015 e maio de 2016 em função das amostras (gramínea, capim-mombaça e solo exposto).

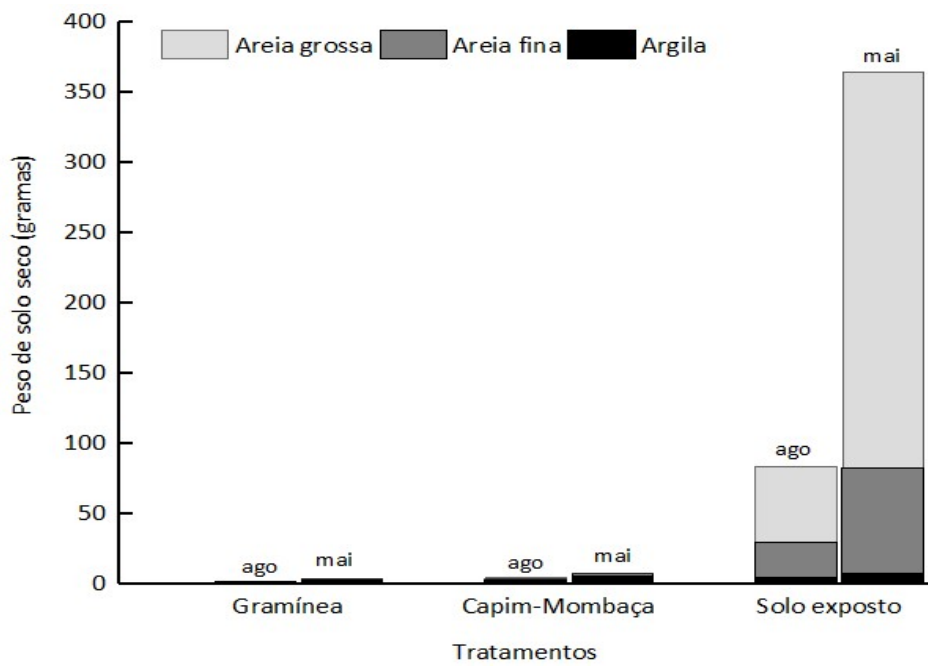

Figura 6: Valores de areia grossa, areia fina e argila nas amostras erodidas na simulação em função das amostras de solo em agosto de 2015 e maio de 2016.

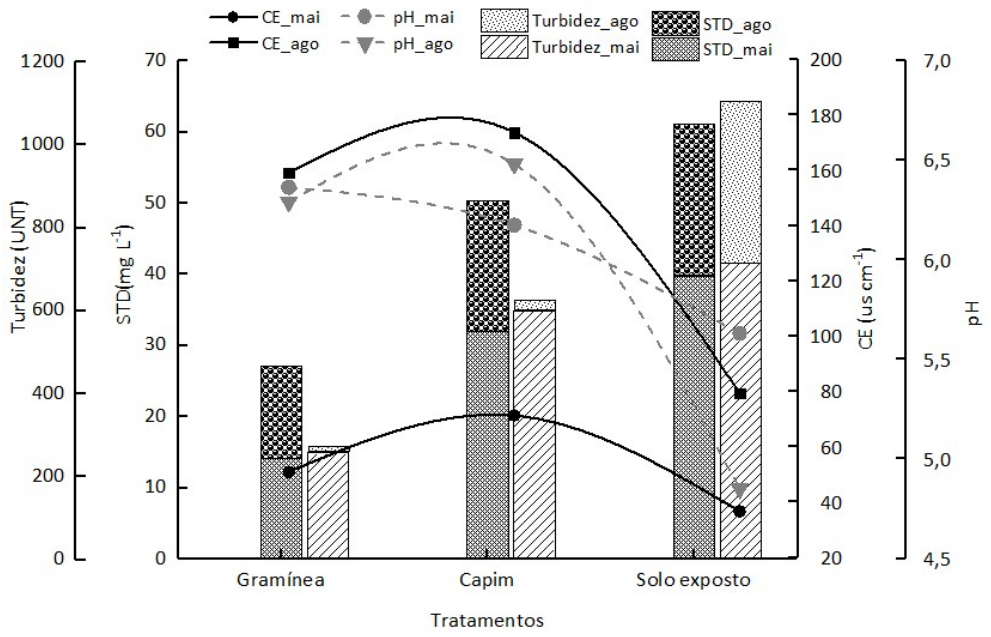

Figura 7: Análises de Condutividade Elétrica (CE), pH, Turbidez e Sólidos Totais Dissolvidos (STD) nas amostras de água erodidas na simulação em agosto de 2015 e maio de 2016.

\section{DISCUSSÃO}

Na série histórica estudada (1990-2016) a maior concentração de chuva ocorre em maio, período mais chuvoso. Nos anos de 1995 e 2010 ocorreram extremos de chuva, com valores entre 90 a 100 mm de 
precipitação mensal, respectivamente (Figura 3), mas m agosto de 2015 e maio de 2016, observou-se que as chuvas máximas foram de $30 \mathrm{~mm}$ e $70 \mathrm{~mm}$, respectivamente. Souza et al. (2012) encontraram resultados semelhantes ao do presente estudo, obtendo valores de intensidade de precipitação de $86,2 \mathrm{~mm}$ com duração de 30 minutos nos períodos mais chuvosos.

O potencial erosivo mensal, representado na (Figura 4), na série histórica estudada (1990-2016), observou-se que, em toda série histórica, as chuvas diárias acima de $30 \mathrm{~mm}$ são mais ocorrentes no mês maio e, consequentemente maiores erosividades. Esses valores estão de acordo com os resultados de anomalias positivas nos meses de maio e agosto do mesmo período, confirmando que em períodos extremamente chuvosos o processo erosivo no solo torna-se mais acentuado.

\section{Perdas Erosivas Simuladas}

No mês de agosto (período menos chuvoso) na primeira simulação com duração de 30 minutos, em solo seco, foram necessários $4000 \mathrm{~mm}$ de água para iniciar as perdas hídricas, em todas as parcelas analisadas. Nesse período, as amostras que continham solo com gramínea paisagística (Axonopus compressus) e capim-mombaça (Panicum maximum), o volume da amostra erodida, na saída do simulador, foram maiores comparado a amostra do solo exposto (Figura 5), apresentando conteúdo hídrico praticamente limpo, indicando que a cobertura do solo favorece o escoamento superficial sem perdas de solo no início das chuvas. Já em solo exposto, as perdas foram menores, apontando que nesse primeiro momento da simulação, a água infiltrou e, só no segundo momento foi iniciado o processo de perda do solo.

Na segunda simulação, no mês de agosto, com duração de 10 minutos usando 9000 mm de água, simulando chuva torrencial, notou-se que quando o solo já se encontrava saturado, contendo água da primeira simulação, a amostra com solo exposto obteve maior perda de solo comparado com as amostras que continha gramínea e capim-mombaça, ocorrendo o contrário da simulação anterior (Figura 5). A amostra erodida do solo exposto apresentou coloração escura, reforçando que houve maior perda de partículas sólidas nessa parcela.

No mês de maio (período mais chuvoso) o resultado da primeira simulação (4000 mm de água em 30 minutos) ocorreu de forma diferente da primeira simulação do mês de agosto (Figura 5). Foi possível observar que, como o solo já se encontrava saturado devido ao período sazonal das chuvas, contendo umidade no solo, o processo erosivo ocorreu logo nos primeiros minutos da simulação, principalmente na parcela com solo exposto. Já na segunda simulação (9000 mm de água em 10 minutos), o processo erosivo ocorreu intensamente nos três tipos de solo, porém as perdas no solo exposto foram mais expressivas. Isso pode ser explicado pela falta de cobertura vegetal, a ausência de estrutura foliar e radicular facilita as perdas de solos, o escoamento superficial e transporte de sedimentos. A água da chuva simulada infiltrou no solo até o momento de atingir a capacidade máxima de retenção hídrica do mesmo, o qual após a saturação percebeu o início do escoamento superficial, transportando os materiais sólidos presentes nas parcelas.

Esses resultados corroboram com os estudos de Silva et al. (2005) que destacaram a influência de eventos pluviais no grau de erosividade, estando fortemente associados ao volume e o tempo de duração da 
chuva, pois a água preenche os poros do solo rapidamente, iniciando assim o fluxo hídrico superficial. Quando o solo está seco, suas partículas ficam mais afastadas, possuindo no primeiro momento a capacidade de absorver água. Com o solo úmido sua estrutura fica mais agregada, porém, como o solo já se encontra com uma taxa de saturação, ocorre o preenchimento rápido de seus poros por água, facilitando o arraste dos sedimentos mais rapidamente.

Para as análises químicas das amostras erodidas coletadas na saída do simulador, juntou-se as amostras da primeira e segunda simulação para cada amostra de solo, nos dois períodos estudados. Em agosto de 2015 e março de 2016, depois que as amostras erodidas foram separadas em porção sólida e líquida, foi possível observar a real parcela da perda do solo nas simulações de chuvas. Na amostra que continha solo exposto, as perdas foram superiores em relação às demais amostras, e esses resultados foram maiores em março (período chuvoso) (Figura 6). A porção erodida do solo exposto apresentou conteúdo de areia grossa, areia fina e argila mais elevada, tornando a amostra mais turva e, consequentemente, possuindo maiores valores na turbidez da água. Reforçando que esse tipo de solo possui alta capacidade de perdas por erosão hídrica em relação aos dois tipos de cobertura de solo, onde a camada superficial de vegetação favorece apenas a perda de água, reduzindo o transporte de sedimentos. As amostras com a gramínea e capim-mombaça, apesar de serem espécies do tipo forrageiras, houve diferença na capacidade de perdas de solo e água. A gramínea por apresentar um sistema radicular bastante denso e área foliar próxima à superfície do solo, o processo durante as simulações indicaram reduções à erosão em relação às outras parcelas. Dessa forma, a gramínea exerce um efeito de um filtro, diminuindo o tempo de perdas pela infiltração e redução de possíveis sólidos presentes, originando água límpida no recipiente de coleta.

A amostra do solo que continha capim-mombaça, por sua vez apresentou uma elevada quantidade de sedimentos, isso ocorre pelo fato da planta possuir um desenvolvimento diferenciado da gramínea, deixando áreas do solo mais exposta e, consequentemente sujeito aos impactos das gotículas de água da chuva simuladas. O sistema radicular do capim-mombaça não é eficiente para manter todo solo coberto, deixando-o vulnerável ao processo erosivo. Assim sendo, esses resultados reforçam que dependendo da época do ano e da fase fenológico do capim-mombaça e de outras gramíneas podem ocorrer exposições do solo ao processo erosivo, acarretando perdas irreversíveis em áreas com pastagens mal conservadas.

Os valores de turbidez foram maiores na amostra com solo exposto, indicando que em solo descoberto e no período chuvoso o transporte de sedimentos é mais intenso e, por conseguinte o solo está mais suscetível ao processo erosivo. A quantidade de particulados transportados na amostra erodida de solo exposto foram superiores às demais coberturas, elevando a turbidez nessa parcela da amostra (Figura 7).

A amostra do solo que continha cobertura com gramínea foi o que teve menor turbidez, com valores crescentes no período chuvoso (maio). Esse resultado pode ser explicado pela agregação devido à camada foliar e radicular das gramíneas, reduzindo a erosão hídrica e consequentemente a turbidez. Nesse sentido, os processos erosivos em solos expostos são bem mais acentuados comparados aos que apresentam cobertura vegetal. A água, à medida que percola o solo, cria canais, que vão desestruturando o solo, iniciando 
assim a erosão do solo. O sistema radicular da vegetação evita o surgimento de processos erosivos (CASSOL et al., 2007).

Sabe-se que as partículas erodidas irão influenciar tanto na turbidez quanto nos sólidos totais dissolvidos, bem como na condutividade elétrica. Dependendo da quantidade de sedimento presente na amostra, irá influenciar na presença de sais, componentes não iônicos e compostos orgânicos presente na água. Desta forma, na parcela de solo exposto e no capim-mombaça obtiveram maiores resultados de turbidez e consequentemente de sólidos totais dissolvidos.

Os resultados encontrados de pH (Figura 7) nas amostras não tiveram muitas alterações, no entanto, os valores são mais baixos na amostra de solo exposto. Os valores estão dentro dos padrões estabelecidos de águas naturais, que fica entre 4 a 9. Os valores encontram-se dentro das características da região (SODRÉ, 2007), com valores variando entre 4,85 (mínimo) e 6,39 (máximo) nos resultados dos experimentos.

Já nos resultados de condutividade elétrica (Figura 7), a parcela que apresentou maior valor foi a porção de solo com gramínea e capim-mombaça. Isso pode ser explicado pela maior fração de diversidade, concentrações iônicas e substancias que se dissociam em cátions e ânions presente nas amostras 1 e 2 . (SODRÉ, 2007). O solo exposto, por ser um solo pobre em nutrientes possui menos compostos químicos e orgânicos, diminuindo, dessa forma, a presença de concentrações iônicas nas amostras.

\section{CONCLUSÕES}

O potencial erosivo anual na série histórica estudada tiveram maiores precipitações e consequentemente maiores erosividades nos meses de maio (1990 a 2016). A erosão do solo é mais intensa no período chuvoso (maio) em relação ao menos chuvoso (agosto) em solo exposto, seguido do capimmombaça para as condições em que foram realizadas as simulações em Belém/PA. A gramínea apresenta maior capacidade de retenção de solo em eventos pluviosos simulados. A cobertura do solo, área foliar e a densidade do sistema radicular condicionam as perdas de solo e água, sendo indicativos de manutenção da vegetação em sistemas de produção devido ao alto potencial erosivo das chuvas em Belém/PA. O simulador portátil é um excelente instrumento de avaliação do potencial de perdas de solo e água em eventos erosivos, principalmente porque se trata de uma ferramenta de conscientização ambiental, pois mostra na prática a dinâmica de perdas do solo em condições diferentes de conservação do mesmo.

\section{REFERÊNCIAS}

BERTONI, J.; LOMBARDI NETO, F.. Conservação do solo. 8 ed. São Paulo: Ícone, 2012.

CASSOL E. A.; LEVIEN R.; ANGHINONI I.; BADELUCCI M. P.. Perdas de nutrientes por erosão em diferentes métodos de melhoramento de pastagem nativa no Rio Grande do Sul. Revista Brasileira de Ciência do Solo, v.26, p.705-712, 2002.

CASSOL, E. A; DENARDIN, J. E.; KOCHHANN, R. A.. Sistema plantio direto: evolução e implicações sobre a conservação do solo e da água. In: CERETTA, C. A.; SILVA, L. S.; REICHERT, J. M.. Tópicos em ciência do solo. Sociedade Brasileira de Ciência do Solo, Viçosa, v.1, p.333-369, 2007.
HERNANI, L. C.; FREITAS, P. L.; PRUSKI, F. F.; DE MARIA, I. C.; CASTRO FILHO, C.; LANDERS, J. C.. A erosão e seu impacto. In: MANZATTO, C. V.; FREITA JÚNIOR, E.; PERES, J. R. R.. Uso agrícola dos solos brasileiros. Rio de Janeiro: Embrapa Solos, 2002.

MARTORANO, L. G.; LISBOA, L.; MEIRELLES, M. S. P.; SCHULER, A.. Erosive Potential of Rainfalls in the Climate Change Scenarios in the Upper Taquari River Basin, MS, Brazil. In: CONFERENCE ON INTERNATIONAL RESEARCH ON FOOD SECURITY, NATURAL RESOURCE MANAGEMENT AND RURAL DEVELOPMENT. Anais. Hamburg: 2009. 
MARTORANO, L. G.; PEREIRA, L. C.; COSTA, A. C. L.. Variabilidade da Precipitação pluviométrica em Belém-Pará Associada ao Fenômeno 'El Niño'. In: CONGRESSO BRASILEIRO DE METEOROLOGIA, 7. Anais. São Paulo: 1992.

MIRANDA, G. A.; MATRANGOLO, W. J. R.; MOREIRA, J. A. A.; REZENDE, M. Q.. Utilização de um simulador de erosão como ferramenta de educação ambiental. Sete Lagoas: Embrapa Milho e Sorgo, 2010

NUNEZ, J. E. V.; SOBRINHO, N. M. B. A.; MAZUR, N. Consequências de diferentes sistemas de preparo do solo sobre distribuição química e perdas de fósforo de um argissolo. Bragantia, Campinas, v.62, n.1, p.101-109, 2003.

OLIVEIRA JUNIOR, R. C.. A erosividade das chuvas na parte leste do Estado do Pará. Dissertação (Mestrado) Universidade Federal Rural da Amazônia, Belém, 1988.

PEREIRA, J. B.; FERNANDES, L. A.; BECEGATO, V. A.; SILVA, S. A.. Erosividade na bacia de drenagem do reservatório de Cachoeira Dourada - Go/MG, Geofocus (Artículos). Revista
Internacional de ciência y tecnologia de la informatión geográfica, n.9, p.290-316, 2009.

SILVA, D. D.; PRUSKI, F. F.; SCHAEFER, C. E. G. R.; AMORIM, R. S. S.; PAIVA, K. W. N.. Efeito da cobertura nas perdas de solo em um argissolo vermelho amarelo utilizando simulador de chuva. Engenharia. Agrícola, Jaboticabal, v.25, n.2, p.409419, 2005.

SODRÉ, S. S. V.. Hidroquímica dos lagos Bolonha e Água Preta, mananciais de Belém-Pará. Dissertação (Mestrado em Ciências Ambientais) - Universidade Federal do Pará, Belém, 2007.

SOUZA, R. O. R. M.; SCARAMUSSA, P. H. M.; AMARAL, M. A. C. M.; PEREIRA NETO, J. A.; PANTOJA, A. V.; SADECK L. W. R. Equações de chuvas intensas para o Estado do Pará. Revista Brasileira de Engenharia Agrícola e Ambiental, Campina Grande, v.16, n.9, p.999-1005, 2012.

WATRIN, O. S.; SANTOS, D. B. O.; VALENTE, M. A.. Bases de dados geográficos como subsídio à gestão territorial na Fazenda experimental da Embrapa Amazônia Oriental. Belém: Embrapa Amazônia Oriental, 2011.

A CBPC - Companhia Brasileira de Produção Científica (CNPJ: 11.221.422/0001-03) detém os direitos materiais desta publicação. Os direitos referem-se à publicação do trabalho em qualquer parte do mundo, incluindo os direitos às renovações, expansões e disseminações da contribuição, bem como outros direitos subsidiários. Todos os trabalhos publicados eletronicamente poderão posteriormente ser publicados em coletâneas impressas sob coordenação da Sustenere Publishing, da Companhia Brasileira de Produção Científica e seus parceiros autorizados. Os (as) autores (as) preservam os direitos autorais, mas não têm permissão para a publicação da contribuição em outro meio, impresso ou digital, em português ou em tradução. 